\title{
NOVO DESENVOLVIMENTISMO, LULISMO, CONFLITO SOCIAL E ESTADO NO BRASIL
}

\section{NEW DEVELOPMENTALISM, LULISMO, SOCIAL CONFLICT AND STATE IN BRAZIL}

\author{
Rodolfo Soares Moimaz \\ Instituto de Filosofia e Ciências Humanas, Universidade Estadual de Campinas (Unicamp). Rua Cora Coralina, \\ 100 - Cidade Universitária, 13083-896 Campinas, São Paulo, Brasil. Email: moimaz@gmail.com ${ }^{1}$
}

\begin{abstract}
Resumo: $\mathrm{O}$ texto que se segue realiza uma reflexão crítica acerca das abordagens sobre o novo desenvolvimentismo (Aloizio Mercadante Oliva) e o lulismo (André Singer), a partir das caracterizações sobre a autonomia do Estado durante os governos Lula/PT (Partido dos Trabalhadores) frente às classes sociais. Os contrapontos aqui elencados são trazidos por Armando Boito Jr., em sua discussão sobre bonapartismo e as disputas entre fraç̃oes de classe; por Bernardo Mançano Fernandes, que questiona a existência de interesses comuns entre classes sociais antagônicas no campo; com Plínio Arruda Sampaio Jr., que argumenta sobre as relações entre a manutenção da segregação social e a dependência externa; e fundamentados na interpretação de Florestan Fernandes acerca da composição social histórica da burguesia brasileira.
\end{abstract}

Palavras-chave: novo desenvolvimentismo, lulismo, Estado, classes sociais.

\begin{abstract}
This text critically reflects on new developmentalism (Aloizio Mercadante Oliva) and Lulism (André Singer). It is based on the analyses that both authors develop on State's autonomy in relation to social classes, during the Lula/PT (Workers Party) governments. The discussion is based on the work by Armando Boito Jr., in his reflection of Bonapartism and the disputes between class fractions; Bernardo Mançano Fernandes, who questions the existence of common interests among antagonistic social classes in the countryside; Plínio Arruda Sampaio Jr., an author that argues about the relationship between the maintenance of social segregation and external dependence; and Florestan Fernandes, with his interpretation of the historical social composition of the Brazilian bourgeoisie.
\end{abstract}

Keywords: new developmentalism, lulismo, State, social classes.

\section{Introdução}

Entre 2003 e abril de 2016, o Brasil foi governado pelo Partido dos Trabalhadores - e suas coalizões. Diferentes estudos sobre este período visam compreender as características deste momento histórico, abordando questões diversas, desde as diretrizes políticas, econômicas e sociais destes governos, até as possíveis transformações ocorridas - ou não - na estrutura social brasileira a partir dos projetos então implementados.

Neste trabalho, será realizada uma reflexão acerca de alguns destes estudos, com destaque a dois importantes intelectuais ligados ao Partido dos Trabalhadores: Aloizio Mercadante Oliva, com a tese do novo desenvolvimentismo; e André Singer, 
com a discussão do lulismo. Assim, serão debatidas as abordagens realizadas por estes autores acerca das características do Estado, em especial sob presidência de Lula [Luís Inácio Lula da Silva] (2003-2010), no que diz respeito às possibilidades de implementação de medidas de transformação social - estruturais ou não, a depender do autor - , com relativa autonomia frente as classes sociais no Brasil. Em outras palavras, como se, a partir das políticas de governo, fosse possível a efetivação de um reequilíbrio de forças entre as classes sociais, através do qual todas seriam, de certa forma, beneficiadas ${ }^{2}$.

Após a breve apresentação destas teses, serão elencadas outras contribuições, como as de Armando Boito Jr., Bernardo Mançano Fernandes, Plínio de Arruda Sampaio Jr. e Florestan Fernandes. Suas reflexões permitem a elaboração de indagações acerca das chances de efetivação deste equilíbrio entre classes sociais. Boito Jr. apresenta questões importantes acerca das classes sociais nos governos PT e dos privilégios à grande burguesia interna, buscando demonstrar as impossibilidades destes governos terem encabeçado um "programa" do subproletariado, uma enorme parcela da população não organizada como classe. Em seguida, a partir de Bernardo M. Fernandes, Plínio A. Sampaio Jr. e Florestan Fernandes, pode-se discutir as limitações de um projeto de desenvolvimento dito autônomo, mas feito em conciliação com a burguesia, atrelado a setores como o agronegócio, em uma economia periférica dependente.

Assim, com a retomada de importantes e divergentes caracterizações sobre a realidade brasileira, o objetivo deste texto é realizar um debate teórico crítico acerca das leituras sobre a autonomia do Estado apresentado nos governos do PT, especialmente entre 2003-2010, resgatando elaborações e questões acerca das relações de classe historicamente constituídas no país.

As hipóteses aqui apresentadas são as de que, ainda que haja contribuições que defendam que estes governos, por distintos motivos, conseguiram aplicar políticas sociais com maior ou menor grau de independência em relação às classes sociais, há características históricas decorrentes da formação social brasileira que se traduzem em limitações estruturais à efetivação de um projeto político que se pretenda autônomo (ainda que apenas relativamente), sem tensionamentos com a ordem social, de conciliação entre classes sociais antagônicas.

\section{O novo desenvolvimentismo e a autonomia relativa do Estado brasileiro}

Nesta seção serão discutidas algumas contribuições de Aloizio Mercadante Oliva e André Singer. A escolha desses autores não é ao acaso: ambos são importantes 
referências ligadas ao Partido dos Trabalhadores. Oliva, além de Senador durante os governos Lula, assumiu cargos de Ministro da Ciência, Tecnologia e Inovação, Ministro da Educação e Ministro-Chefe da Casa Civil (entre 2011-2015), e formulou a tese As bases do novo desenvolvimentismo: Análise do governo Lula (2010), que sistematiza uma significatvia interpretação do chamado novo desenvolvimentismo. Singer foi Secretário de Imprensa do Palácio do Planalto (2005-2007), além de porta-voz da Presidência da República entre 2003-2007, no primeiro mandato do governo Lula. $\mathrm{O}$ autor elaborou trabalhos essenciais que são referência para a construção de análises críticas dos governos PT, bem como das conformações das classes sociais que embasam discussões contemporâneas no Brasil.

\title{
Oliva e o novo desenvolvimentismo
}

O novo desenvolvimentismo é um conceito reivindicado por diferentes autores, que vão explicá-lo a partir de distintos pontos de partida. O foco aqui se dá sobre a tese de Oliva, que, a partir de sua localização nos governos do PT, buscou sistematizar uma interpretação sobre políticas planejadas e aplicadas no período.

Para o autor, a partir do primeiro governo Lula, em 2003, o Brasil viveria uma inflexão histórica; isto porque, pela primeira vez, o país passou a ter um Estado que se estruturaria a partir do eixo social:

\begin{abstract}
A sociedade brasileira se desenvolveu sob o signo da concentração da terra e do poder político e da exclusão social. Essa matriz originária, embora tenha assumido expressões distintas, em função de mudanças no sistema de produção e nas formas de organização política do Estado, praticamente não se modificou ao longo do tempo, mesmo quando, em algumas fases, a expansão acelerada da economia atenuou as manifestações mais agudas da pobreza e da desigualdade. (...) a evolução recente da economia brasileira representa uma inflexão histórica nessas tendências estruturais. (...) Com efeito, o social passou a se constituir num dos eixos estruturantes do novo processo de desenvolvimento brasileiro. (Oliva, 2010, p. 25-26, grifos do autor)
\end{abstract}

Dessa forma, analisando o processo de desenvolvimento do país a partir de 2003, o autor afirma que, mais que implementar políticas sociais, esta nova orientação política teria representado profundas rupturas com o neoliberalismo e com a estrutura social do país, marcada pela exclusão social. Este ousado projeto de transformação da sociedade brasileira seria o novo desenvolvimentismo.

Para o autor, o novo desenvolvimentismo teria como marcas o combate à pobreza, com inclusão social e distribuição de renda, além de características como: sólida estabilidade econômica; o social como eixo do projeto de desenvolvimento; a consolidação da democracia e das instituições do Estado republicano; 
maior protagonismo do Brasil no cenário econômico internacional; a sustentabilidade ambiental como parte das políticas de desenvolvimento; o estímulo à produção de conhecimento no país; com educação de qualidade para o conjunto da população (Oliva, 2010).

A implementação deste projeto contrariaria interesses de camadas políticas tradicionais e conservadoras do país. Nesse sentido, Oliva destaca, por um lado, a importância da figura de Lula, que, através de suas qualidades pessoais, seria elemento-chave para a viabilização do novo desenvolvimentismo; e, por outro, o amadurecimento da democracia brasileira, com a incorporação de representantes de movimentos sociais e centrais sindicais na elaboração das políticas governamentais.

Portanto, este projeto seria símbolo da consolidação democrática do país, e indicaria uma cisão com as formas pelas quais os aparelhos do Estado foram utilizados ao longo da história. Isto porque, até então, o Estado sempre havia sido

fortemente capturado pelos interesses privados dos estratos econômicos dominantes. O seu caráter essencialmente patrimonialista, presente desde sua formação, foi reproduzido por nosso capitalismo tardio, mesmo ao longo da história brasileira recente. Trata-se essencialmente de um Estado "privatizado", muito permeável às pressões do capital, mas ainda resistente à incorporação das reivindicações dos setores populares em suas políticas e em seu processo decisório. Com alarmante frequência, os movimentos sociais organizados foram, ainda no período da redemocratização brasileira, criminalizados, obedecendo à lógica repressiva da República Velha de tratar a questão social como "caso de polícia”. (Oliva, 2010, p. 24)

Um Estado "privatizado" agravaria as desigualdades sociais, impedindo a efetivação políticas públicas. Assim, a estruturação de instituições cuja finalidade seria o controle da máquina pública (como o Ministério Público, Polícia Federal, etc.), efetivadas a partir dos governos Lula, seria essencial no combate ao clientelismo e o patrimonialismo, que ainda pressionariam o Estado brasileiro (Oliva, 2010).

Dessa forma, pode-se perceber que, para o autor, a partir da liderança do Partido dos Trabalhadores, e, principalmente, do ex-presidente Lula, seria possível ao Estado brasileiro "enfrentar o desafio lançado por [Celso] Furtado" (Oliva, 2010, p. 6), rumo ao desenvolvimento nacional com autonomia e estabilidade, atendendo aos interesses da população. Estas decisões políticas do governo, porém, precisariam de recursos para efetivação.

Para Oliva, um dos setores fundamentais para a geração de recursos que viabilizariam os projetos políticos, econômicos e sociais neodesenvolvimentistas seria o agronegócio. Isto é, a partir de 2003, o governo brasileiro teria concentrado esforços 
para direcionar os saldos econômicos positivos das exportações do agronegócio para áreas sociais. Se, para diversos autores (Fernandes, 2006; Fernandes, 2010; Prado Jr., 1987; etc.), seria paradoxal articular os interesses dos grandes proprietários de terras com políticas de igualdade social, Oliva, em sentido oposto, afirma que "A agricultura $^{3}$ é uma atividade extremamente importante para a economia brasileira e foi fundamental na implementação das políticas de estabilização econômica, crescimento e distribuição de renda do Governo Lula." (Oliva, 2010, p. 229).

Assim, os resultados obtidos pelo agronegócio - em 2010, o país se destacou como o maior exportador de soja, carne bovina, carne de frango, suco de laranja e café do mundo, e o terceiro maior produtor de milho e frutas (Oliva, 2010) -, teriam permitido aos governos Lula a superação da "herança maldita" deixada pelos governos anteriores.

Outra área que teria registrado avanços, a partir dos excedentes gerados pelo setor agroexportador, seria a reforma agrária. Para Oliva, neste período, a agricultura familiar teria se desenvolvido em decorrência da política de crédito implementada pelo governo federal: "entre 2003 e 2009, foram criados 3.348 assentamentos, abrangendo uma área de 46,7 milhões de hectares, que beneficiaram um total de 574.609 famílias." (Oliva, 2010, p. 165).

Em síntese, para Oliva, houve, de fato, um volumoso financiamento público para toda a agricultura, em proporções distintas - a partir do tipo de produção implementada, do grau tecnológico, do tamanho da unidade produtiva, de qual o cultivo realizado, etc. Isto é, a safra de 2009/10 contou com orçamento de $\mathrm{R} \$ 107,5$ bilhões - quase cinco vezes superior ao financiamento de 2002 - , sendo que, destes, R \$ 92,5 bilhões foram disponibilizados para a "agricultura empresarial", e R \$ 15 bilhões à agricultura familiar (Oliva, 2010). Porém, esta diferença de financiamento não implicaria, para o autor, proteção aos interesses do setor agroexportador em detrimento dos estratos mais pauperizados. Isto porque, com os resultados positivos nas exportações do agronegócio, o governo brasileiro poderia desenvolver programas sociais que beneficiariam as classes populares. Assim, para Oliva, o financiamento ao setor agroexportador seria uma política de interesse nacional.

Tais ações, afirma o autor, acabariam se chocando com interesses tradicionais e conservadores da sociedade brasileira. Nesse sentido, os governos Lula só teriam condições de aplicar o novo desenvolvimentismo por conta de sua grande base popular de apoio, apesar dos limites impostos pelo chamado "presidencialismo de coalisão".

Assim, durante este período, teria sido possível a realização de mudanças estruturais na sociedade brasileira, uma "inflexão histórica" (Oliva, 2010) rumo à igualdade social, que só seria concretizada mediante o estabelecimento de alianças 
com setores que, anteriormente, eram considerados inimigos das pautas sociais como o agronegócio.

O conflito entre classes sociais, que, no passado, parecia inevitável, na análise de Oliva (2010), seria atenuado pela intervenção do governo federal. Para o autor, não teriam acabado os conflitos sociais, mas estes teriam se deslocado para o antagonismo entre esquerda $x$ direita, sendo a direita representada pelos setores que defenderiam a implementação do neoliberalismo nos moldes dos governos anteriores, do PSDB (Partido da Social Democracia Brasileira), diretamente ligados ao mercado financeiro internacional, além da grande mídia; enquanto a esquerda seria composta pelos setores que teriam a obrigação histórica de defender o governo neodesenvolvimentista, que estaria atendendo as demandas populares, cuja linha de frente seriam os sindicatos, partidos políticos de esquerda e demais movimentos sociais.

\section{Singer e o lulismo}

Outros autores não caracterizam que os governos do PT tenham representado uma "inflexão histórica", mas poderiam ser classificados como reformistas, tendo aplicado um reformismo fraco, sem ameaças à ordem estabelecida (Singer, 2012). Nestas interpretações, a eleição de 2002, vencida pelo Partido dos Trabalhadores, sob a liderança de Lula, teria aberto um momento histórico que resultou, especialmente a partir de 2006, em um fenômeno classificado por Singer como lulismo. De acordo com o autor,

Teria havido, a partir de 2003, uma orientação que permitiu, contando com a mudança da conjuntura internacional, a adoção de políticas para reduzir a pobreza - com destaque ao combate à miséria - e para a ativação do mercado interno, sem confronto com o capital. Isso teria produzido, em associação com a crise do "mensalão", um realinhamento eleitoral que se cristaliza em 2006, surgindo o lulismo. O aparecimento de uma base lulista, por sua vez, proporcionou ao presidente maior margem de manobra no segundo mandato, possibilitando acelerar a implantação do modelo "diminuição da pobreza com manutenção da ordem" (Singer, 2012, p. 13)

Para o autor, ainda que, em números absolutos, as eleições de 2002 e 2006 sejam semelhantes, em 2006 teria havido um realinhamento eleitoral principalmente nos setores de baixíssima renda e nos setores médios. Diferente das outras eleições, os eleitores de baixíssima renda passariam a votar em Lula, enquanto os setores médios se afastariam, por conta da chamada crise do "mensalão", em 20054. Comparando as votações do Partido dos Trabalhadores e as de Lula, Singer (2012) registra que o PT teve maior votação na parcela da população com maior IDH (Índice de Desenvolvimento Humano), enquanto Lula apresentou resultados muito superiores nas regiões mais pobres do país. 
Dessa forma, para Singer (2009), a reeleição de Lula teve como característica fundamental a mudança do perfil social de seus eleitores. Diferente do ocorrido em 2002, a fração de classe que garantiu, pelos votos, a vitória do candidato do Partido dos Trabalhadores e então presidente, foi o subproletariado. Para o autor, o subproletariado é composto por aqueles que

oferecem a sua força de trabalho no mercado sem encontrar quem esteja disposto a adquiri-la por um preço que assegure sua reprodução em condições normais. Estão nessa categoria empregados domésticos, assalariados de pequenos produtores diretos e trabalhadores destituídos das condições mínimas de participação na luta de classes. Para encontrar uma maneira de quantificá-los, (...) seria razoável considerar subproletários os que tinham renda de até um salário mínimo per capita e metade dos que tinham renda de até dois salários mínimos per capita. De acordo com esse critério, $63 \%$ do proletariado era constituído por subproletários (...) [ou] 48\% da PEA [População Economicamente Ativa]. (Singer, 2009, p. 98)

Assim, para Singer, através do resultado eleitoral de 2006, pode-se refletir sobre as possibilidades de o lulismo ter aberto uma nova via para a política nacional, de representação institucional desta camada de trabalhadores (Singer, 2012). Este setor social concentraria uma "fusão" de elementos ideológicos ligados à esquerda e à direita, de modo que teria como expectativa a eleição de um governo que agisse para a diminuição das desigualdades sociais, sem, porém, ameaçar a ordem estabelecida (Singer, 2009).

Para o autor, a reeleição de Lula não teria sido motivada pelo candidato ter sido referência nas greves das décadas de 1970-80; inclusive, estes processos de mobilização teriam mais rejeição justamente nos setores mais pauperizados da população - ao contrário do que o senso comum poderia sugerir, os setores mais empobrecidos da população seriam mais hostis às greves (Singer, 2009). Por isso, nas eleições de 1989, os mais pobres votaram majoritariamente em Collor (candidato da direita), enquanto os setores médios, em Lula.

Nesse sentido, as eleições de 2006 chamam a atenção de Singer. O desgaste do governo em 2005, com a perda de apoio da base social dos setores médios poderia tê-lo derrubado. Porém, neste período, Lula se fortaleceu nas regiões mais pobres do país, a partir da implementação de diversos programas sociais como, por exemplo:

aos poucos a quantidade de recursos destinados ao PBF [Programa Bolsa Família] o converteu em uma espécie de renda mínima para todas as famílias brasileiras que comprovassem situação de extrema necessidade. Em 2004, o PBF recebeu verba $64 \%$ maior e, em 2005, ano do "mensalão", teve um aumento de outros $26 \%$, mais do que duplicando o número de famílias atendidas, de 3,6 milhões para 8,7 milhões, em dois 
anos. Entre 2003 e 2006, a Bolsa Família viu o seu orçamento multiplicado por treze, pulando de $\mathrm{R} \$ 570$ milhões de reais para 7,5 bilhões de reais, atendendo a cerca de 11,4 milhões de famílias perto da eleição de 2006 (Singer, 2009, p. 91)

O Programa Bolsa Família (PBF) não explicaria, por si só, os resultados de Lula nas eleições. Para o autor, junto ao PBF, medidas como os aumentos reais do salário-mínimo, o aumento na disponibilização de crédito para a população, o Programa Luz Para Todos, etc., eram traduzidos em resultados eleitorais: quanto maior a porcentagem da população assistida pelas políticas do governo, maior sua votação (Singer, 2009). Assim, o subproletariado se apresentou como linha de frente na reeleição de Lula.

Para Singer, a eleição de Lula em 2006 demonstrou um esvaziamento ideológico em relação ao conflito entre classes sociais; por exemplo, mais de um quarto dos eleitores não sabiam se localizar entre a esquerda e a direita. Por outro lado,

entrou em cena uma força nova, constituída por Lula à frente de uma fração de classe antes caudatária dos partidos da ordem e que, mais do que um efeito geral de desideologização e despolitização, indicava a emergência de outra orientação ideológica, que antes não estava posta no tabuleiro. Parece-nos que o lulismo, ao executar o programa de combate à desigualdade dentro da ordem, confeccionou nova via ideológica, com a união de bandeiras que não pareciam combinar. (Singer, 2009, p. 98, grifos do autor)

Ou seja, mesmo os elementos de continuidade de uma política econômica ortodoxa, como sequência dos governos FHC (Fernando Henrique Cardoso, do PSDB), no início do primeiro mandato do Partido dos Trabalhadores, teria se dado, dentre outros motivos, com o objetivo de o governo angariar, por conta da bandeira da manutenção da ordem, o apoio dos mais pobres. O PT se tornou o partido "dos pobres" (perdendo a aparência ideológica de ser o partido "dos trabalhadores"), assemelhando-se aos partidos populistas pré-1964 (Singer, 2012).

Nesse sentido, o período de Lula à frente do governo federal se constituiu, para Singer, como a realização do programa do subproletariado. Dessa forma, os governos petistas se apresentaram como representantes do subproletariado, "amoldando-se a ele, mais do que o modelando, porém, ao mesmo tempo, constituindo-o como ator político." (Singer, 2009, p. 99). Com a base social no subproletariado, Singer afirma que Lula conseguiu estabelecer um grau de autonomia que remete ao bonapartismo: "Lula obteve uma autonomia bonapartista (sem qualquer conotação militar). Com ela, criou um ponto de fuga para a luta de classes, que começou a ser arbitrada desde cima ao sabor da correlação de forças" (Singer, 2009, p. 100).

Assim como em Oliva, Singer destaca o conflito social, mas este não apareceria como luta entre as classes sociais antagônicas, ou mesmo entre esquerda e direita. 
A divisão política demonstrada no Brasil seria entre ricos e pobres:

Olulismo, que emerge junto com o realinhamento, é (...) o encontro de uma liderança, a de Lula, com uma fração de classe, o subproletariado, por meio do programa cujos pontos principais foram delineados entre 2003 e 2005: combater a pobreza, (...) sem confrontar os interesses do capital. Ao mesmo tempo, também decorre do realinhamento o antilulismo que se concentra no PSDB e afasta a classe média de Lula e do PT (Singer, 2012, p. 15-16)

Dessa forma, com a consolidação dos governos do PT como representantes do "programa" do subproletariado, teria sido possível separar esta fração de classe frente à burguesia, que tradicionalmente angariava seus votos, principalmente na região Nordeste. Assim, estes governos teriam obtido uma correlação de forças favorável, que os permitiu a realização de um reformismo fraco, "lento e desmobilizador, mas é reformismo" (Singer, 2012, p. 45), e que, de acordo com Singer, por ser a representação política do subproletariado, deveria ser fraco, sem apresentar tendências de rupturas com a ordem.

Portanto, para o autor, seria possível ao governo realizar um equilíbrio entre capital e trabalho, ou entre o capital e subproletariado, sem que nenhuma destas "classes" acumulasse forças o bastante para impor suas demandas - sejam elas um reformismo mais profundo, ou um neoliberalismo radicalizado - às demais classes sociais.

\section{Divergências e convergências}

Conforme exposto acima, os dois autores têm caracterizações distintas acerca dos governos do PT. Para Oliva, o governo federal, quando dirigido pelo Partido dos Trabalhadores, foi capaz de protagonizar uma mudança estrutural na sociedade brasileira, um rompimento com um padrão histórico de desenvolvimento fundado na exclusão e desigualdade social, ainda que com os obstáculos trazidos pelo "presidencialismo de coalizão". Singer, por sua vez, não caracteriza tamanha "inflexão" histórica, mas a implementação de um reformismo fraco, consequência da representação das demandas do subproletariado, que apoiava o governo, tornando assim possível a implementação de ações distributivas por parte do Estado.

Porém, se os autores apresentam divergências, pode-se perceber que, em alguns sentidos, há pontos de convergência. Por exemplo, ainda que cada autor compreenda as possibilidades de ação dos governos do PT de modo distinto, ambos concordam que a direção deste partido no governo federal teria possibilitado a implementação de medidas que trouxeram mudanças importantes para 
a sociedade brasileira - sejam elas "estruturais" ou não. Isso seria possível pelo determinado grau de autonomia destes governos, seja por sua orientação política neodesenvolvimentista, acrescida de uma base social favorável às transformações, seja pela mudança na correlação de forças conquistada através do apoio de uma fração de classe específica e majoritária na população, o subproletariado.

Para ambos, também, os governos Lula teriam alterado a dinâmica dos conflitos sociais no Brasil. Isto é, tanto em Oliva quanto em Singer, as principais disputas não se dariam entre classes sociais antagônicas; para Oliva, o conflito seria entre a esquerda e direita, classificadas a partir do apoio ou oposição ao projeto político implementado pelo governo, enquanto que, para Singer, a principal cisão da sociedade se daria entre ricos e pobres, divididos a partir do quanto seriam atendidos pelos programas sociais do governo federal.

\section{Análises críticas a Singer e Oliva}

Nesta seção são apresentadas reflexões críticas acerca das posições de Singer e Oliva. Para a análise das elaborações de Singer, seguem discussões trazidas por Armando Boito Jr., que buscam problematizar a definição de um "programa" do subproletariado aplicado pelos governos, e as consequências que decorrem dessa prerrogativa. Depois, apresentando questões ao novo desenvolvimentismo de Oliva, são elencados argumentos de Bernardo Mançano Fernandes, Plínio de Arruda Sampaio Jr. e Florestan Fernandes, cujas interpretações acabam por sugerir as limitações de projetos como novo desenvolvimentismo, dito autônomo, mas construído em acordo com os interesses do grande capital.

\section{Armando Boito Jr. e o lulismo}

Em contraposição a elaborações como as de Singer, para Boito Jr. (2013) é um equívoco afirmar que os governos do Partido dos Trabalhadores teriam equilibrado as contradições entre as classes sociais. O autor discorda da interpretação de que estes governos, ao realizarem uma suposta "neutralização" dos interesses antagônicos, estaria colocando em prática o "programa do subproletariado". Na análise de Boito Jr., Singer compreenderia a luta de classes como uma disputa possível de se dar em igualdade entre as classes sociais, como se fosse possível que este conflito ocorresse em "terreno neutro".

Nesse sentido, um questionamento fundamental é realizado por Boito Jr.: o que seria o programa do subproletariado? 
Esta questão tem como elemento central a discussão sobre a caracterização do subproletariado como classe social. Isto é, "Se os setores populares heterogêneos (...) [agrupados] sob essa noção caracterizam-se, justamente, por 'não terem condições de participar da luta de classes', como é que se pode afirmar que eles têm um 'programa'?" (Boito Jr., 2013, p. 173). Ou seja, se um setor social está desorganizado politicamente, ele não possui um programa próprio, e, sem este programa, não há possibilidades de intervenção política. Para o autor, esta massa pauperizada, sem organização política, e que se constituiu como base eleitoral do PT, tinha aspirações, mas estas se apresentariam de modo difuso, e não em um programa. Estes governos teriam organizado tais aspirações através de programas como o PBF.

Também são apresentadas ressalvas acerca do bonapartismo afirmado por Singer. Para o autor, "o Estado capitalista sempre tem um papel ativo que o coloca acima dos interesses imediatos dessa ou daquela classe ou fração e que possibilita que essa instituição busque um equilíbrio instável de compromisso entre as forças em presença." (Boito Jr., 2013, pp. 173-174). Ou seja, as concessões realizadas pelos governos analisados, mesmo que sejam demandadas por forças sociais contraditórias, não indicaria o bonapartismo. Se o bonapartismo se traduz como uma situação na qual o Estado não "os interesses objetivos nem as demandas de nenhuma classe ou fração de classe em presença” (Boito Jr., 2013, p. 174), os governos Lula não foram bonapartistas. Isto porque, para o autor, eles priorizaram os interesses de uma fração de classe ${ }^{5}$ em especial: a grande burguesia interna, e não o subproletariado.

Esta grande burguesia interna estaria

presente em diversos setores da economia nacional - construção naval, construção civil, indústria de transformação, mineração e outros -, embora não seja anti-imperialista, reivindica a proteção do Estado para preservar e melhorar sua posição no capitalismo brasileiro. Uma série de medidas dos governos Lula e Dilma indica o atendimento dessa reivindicação. Cito algumas delas: a política (...) de recuperação da indústria da construção naval, a política de financiamento subsidiado do BNDES, a nova legislação que regulamenta as compras do Estado e das empresas estatais de maneira a priorizar a produção local, a política externa Sul-Sul, (...) e o apoio à conquista de mercados externos pelas grandes empresas brasileiras. (Boito Jr., 2013, p. 175)

É importante destacar que, para o autor, o favorecimento da grande burguesia interna não significaria que os outros setores não teriam tido benefícios. Porém, Boito Jr. (2013) avalia que esta massa de trabalhadores não fez parte do bloco no poder, de modo que, para ela, os ganhos foram desproporcionalmente menores. Isto é, ainda que tenham sido importantes, considerando as condições de vida da 
população brasileira, não podem ser comparados ao volume de recursos e suportes disponibilizados ao grande capital.

O autor também polemiza com a caracterização de que haveria um conservadorismo no subproletariado, e isso teria forçado os governos a realizarem medidas políticas que estivessem nos marcos da ordem, sem rompimentos com o neoliberalismo. Ao contrário, o desejo por redistribuição de renda no país, expressa pelo subproletariado, seria uma demanda progressista. Assim, mais que o neoliberalismo ser mantido por conta do conservadorismo popular existente no Brasil, foi preservado porque "atende a poderosos interesses das grandes empresas e é possível demonstrar que grande parte da burguesia lutou e luta para que pilares desse modelo sejam mantidos." (Boito Jr., 2013, p. 177).

Considerando a heterogeneidade e as disputas existentes entre frações da burguesia, somada à condição de dependência da burguesia interna em relação ao capital internacional, esta não teria conseguido forjar seu próprio instrumento político, que defenderia seus interesses. Por isso, esta fração de classe teria se aproximado do PT - que, de organização criada pela classe trabalhadora, transformou-se em partido neodesenvolvimentista. Se os governos petistas tivessem privilegiado o programa de uma classe subalterna (como seria o caso do subproletariado, compreendido por Singer), ao invés de realizar mudanças sem rompimentos bruscos com a ordem estabelecida, teriam elevando a tensão social ao extremo, justamente por enfrentar, na prática, os interesses das frações burguesas (Boito, 2013).

\section{Questões ao novo desenvolvimentismo de Oliva}

A avaliação de Oliva acerca do neodesenvolvimentismo possui diversos pontos passíveis de questionamentos. Dentre eles, pode-se destacar a proclamada aliança com os setores do agronegócio como fator fundamental ao novo projeto de desenvolvimento do Brasil, enquanto um dos principais motores propulsores de um plano que visaria beneficiar a todas as classes sociais.

Bernardo Mançano Fernandes, por exemplo, aponta uma questão fundamental acerca de análises como as de Oliva, que localizam produtores rurais de todas as classes sociais como partes de um mesmo conjunto. Isto é, para o autor, a utilização do termo agricultura para designar desde a agroindústria exportadora até os assentamentos conquistados por movimentos sociais deve ser problematizada.

Para Fernandes (2013), colocar sob mesma nomenclatura a pequena unidade familiar de produção e o latifúndio camufla as profundas desigualdades existentes no campo. Essa classificação indicaria que todos os sujeitos sociais teriam semelhantes orientações econômicas, políticas, sociais, ideológicas, ou seja, teriam seus interesses acolhidos por um mesmo projeto. 
Assim, o autor propõe a separação dos agentes rurais em dois grupos: os capitalistas e os familiares (Fernandes, 2013). As divergências destes grupos estariam para além das possibilidades de ganhos financeiros; seu antagonismo seria paradigmático. Isto é, agricultura familiar e a capitalista teriam concepções teriam concepções de relação com a terra paradoxais, assim como seriam seus projetos econômicos, políticos e sociais. Com projetos estruturalmente divergentes, seria equivocado o emblocamento destes setores como parte de um só grupo. Isso, necessariamente, invisibilizaria as demandas e propostas de um dos setores, além de esconder a dimensão da contradição, do conflito social (Moimaz, 2015). Portanto, para Fernandes (2013), a exaltação e os saldos positivos do agronegócio representariam o declínio da agricultura familiar.

Conceber o agronegócio como totalidade é uma estratégia do paradigma do capitalismo agrário. Definir todos tão somente como agricultores esconde as diferenças constituídas pelas relações de poder que produzem as desigualdades e mascara, fundamentalmente, as classes sociais. (Fernandes, 2013, p. 200)

Nesse sentido, ao não explicitar as diferenças entre agricultura familiar e capitalista, $\mathrm{o}$ conjunto da produção rural brasileira seria compreendida exclusivamente sob lógica do capital - ou seja, uma orientação política de defesa do agrobusiness. Fernandes destaca como tal lógica expressa os privilégios desse setor: o agronegócio concentrou a maior parte dos recursos destinados ao campo, ocupando enorme extensão de terras, mesmo apresentando baixa empregabilidade, com geração de ganhos proporcionalmente inferiores aos da agricultura familiar - "o agronegócio controla 85\% dos recursos destinados ao crédito agrícola, $76 \%$ da área cultivável, produzindo $62 \%$ do valor bruto e empregando cerca de $26 \%$ das pessoas." (Fernandes, 2013, p. 201). O autor registra também que neste período houve aumento da concentração fundiária: de acordo com o Incra (Instituto Nacional de Colonização e Reforma Agrária), entre 2010 e 2014, as grandes propriedades passaram a ocupar 6 milhões de hectares a mais que no período anterior - um aumento na concentração fundiária de cerca de 2,5\% (Farah, 2015); cabe destacar que, entre 2003 e 2010, estes estabelecimentos passaram de 214,8 milhões para 318 milhões de hectares ocupados (Farah, 2015).

O autor destaca, ainda, que "aceitar a ideologia do agronegócio como único modelo possível inviabiliza a reforma agrária." (Fernandes, 2013, pp. 191-192). Dessa forma não poderia haver reforma agrária em conciliação com os interesses do grande capital agropecuário no Brasil. Essa é uma questão fundamental, considerando que, no novo desenvolvimentismo descrito por Oliva, seria justamente esse setor, o agroexportador, parte estratégica da base aliada dos governos Lula. 
Questionando as possibilidades de conflitos sociais estruturais serem amortecidos por habilidades políticas de uma figura pública, análises como as de Plínio de Arruda Sampaio Jr. (2012) trazem problematizações a partir das teorias do desenvolvimento. Para Oliva, o novo desenvolvimentismo teria como elemento central a "vontade política" dos governos Lula para a resolução de contradições históricas da sociedade brasileira - mesmo sem alteração da estrutura econômica do país, nem enfrentamento a setores historicamente dominantes no Brasil, como os grandes proprietários de terras. Em termos furtadianos (Furtado, 1968), essa "vontade política" seria chave para a internalização dos centros de decisão políticas e econômicas, e esse seria o caminho para o rompimento da situação de dependência da economia brasileira.

Para Sampaio Jr., em uma leitura embasada em Florestan Fernandes, o subdesenvolvimento do país deve ser analisado a partir da dupla articulação entre dependência externa e segregação social. Sem o rompimento desta articulação, estariam comprometidos o controle nacional sobre fins e meios do desenvolvimento (Vargas, 2009).

Não se questiona os obstáculos ao desenvolvimento gerados pela situação de dependência e pelas estruturas responsáveis pela extrema desigualdade social. (...) Em suma, o neodesenvolvimentismo procura (...) a possibilidade de uma política econômica ideal capaz de conciliar crescimento e equidade. Ao identificar a realidade da economia brasileira contemporânea com o desenvolvimento capitalista virtuoso, o novo desenvolvimentista revela-se tal qual é - uma apologia do poder. Não passa de um esforço provinciano para dar roupa nova à velha teoria da modernização como solução para os graves problemas das populações que vivem no elo fraco do sistema capitalista mundial. (Sampaio Jr., 2012, p. 672)

Assim, a superação da condição do subdesenvolvimento passaria pela destruição da condição estrutural de dependência herdada desde o período colonial, ou seja, a inserção submissa dos países economicamente periféricos no mercado internacional, que diminuiria substancialmente as possibilidades de coordenação entre as diretrizes econômicas e os interesses internos destes países, sujeitos aos interesses externos (Furtado, 1968). Assim, seria necessário o enfrentamento ao "latifúndio e os privilégios aberrantes de burguesias dependentes, cuja força se alimenta na pobreza e na miséria de expressivos contingentes da população." (Sampaio Jr., 2012, p. 674).

Portanto, para Sampaio Jr., o novo desenvolvimentismo, ao manter uma economia dependente, baseada na exportação de bens primários e do capital financeiro, com segregação social, representa uma "apologia do poder", uma vez que, sem 
a superação destas características, não seria possível um processo real de desenvolvimento autônomo nacional.

Aprofundando a discussão sobre as possibilidades de conciliação de interesses de classe antagônicos em defesa de um suposto projeto nacional, em um país de economia dependente como o Brasil, cabe retomar algumas discussões de Florestan Fernandes.

Para caracterizar a burguesia brasileira, Fernandes retoma o processo de Independência do país, que rompe com o estatuto colonial. A burguesia brasileira teria passado por um processo de crescimento e diferenciação interna, por consequência da formação de uma rede de serviços - decorrente da organização do Estado nacional - e pelo desenvolvimento urbano (Fernandes, 2006). Assim, sendo um estrato com enormes distinções internas, sua unidade não se dava em torno de interesses comuns, organizados como classe, mas

a maneira pela qual tendiam a polarizar socialmente certas utopias. Pode-se avaliar esse fato através do modo pelo qual os diversos setores dessa ambígua e fluida "burguesia" em formação iria reagir: $1^{\circ}$ ) às ocorrências de uma sociedade na qual imperava a violência como técnica de controle de escravos; $2^{\circ}$ ) aos mores em que se fundavam a escravidão, a dominação senhorial e o próprio regime patrimonialista; $3^{\circ}$ ) à emergência, à propagação e à intensificação de movimentos inconformistas, em que o antiescravismo disfarçava e exprimia o afã de expandir a ordem social competitiva. (Fernandes, 2006, p. 35)

Dessa forma, para o autor, ideais presentes nessa classe social, como o antiescravismo, seriam uma "revolução social dos brancos para os brancos" (Fernandes, 2006, p. 36). Isto porque o enfrentamento à escravidão não se daria por motivações humanistas, mas por ela representar um obstáculo à expansão da economia de mercado e à organização da nação pós-Independência. Nesse sentido, afirma Fernandes, o "burguês" não se apresentaria como uma força social organizada, com autonomia e consciência de seus interesses como classe social. Seu "espírito revolucionário" estaria relacionado a objetivos difusos, egoísticos.

O processo de universalização do trabalho livre, bem como da expansão da ordem competitiva, não teria se dado através do colapso do poder oligárquico. Ao contrário, a construção das estruturas de poder burguês teria ocorrido sob hegemonia da oligarquia, que lidou com essa transição no controle do aparato do Estado. A burguesia, por sua vez, ainda débil, teve como característica as tentativas de influenciar o Estado a tomar medidas que atendessem a seus interesses particulares, pressionando a partir de suas "associações de classe": 
várias burguesias (ou ilhas burguesas), que se formaram em torno da plantação e das cidades, mais se justapõem do que se fundem, e o comércio vem a ser seu ponto de encontro e a área dentro da qual definem seus interesses comuns. É dessa debilidade que iria nascer o poder da burguesia, porque ela impôs, desde o início, que fosse no terreno político que se estabelecesse o pacto tácito (por vezes formalizado e explícito) de dominação de classe. Ao contrário de outras burguesias, que forjaram instituições próprias de poder especificamente social e só usaram o Estado para arranjos mais complicados e específicos, a nossa burguesia converge para o Estado e faz sua unificação no plano político (...). As próprias “associações de clas$\mathrm{se}^{\prime \prime},($...) visavam a exercer pressão e influência sobre o Estado e, de modo mais concreto, orientar e controlar a aplicação do poder político estatal, de acordo com seus fins particulares. Em consequência, a oligarquia não perdeu a base de poder que lograra antes, como e enquanto aristocracia agrária; e encontrou condições ideais para enfrentar a transição, modernizando-se, onde isso fosse inevitável, e irradiando-se pelo desdobramento das oportunidades novas, onde isso fosse possível. (Fernandes, 2006, p. 240)

Nesse sentido, a burguesia brasileira seria distinta de outras burguesias: ela não portaria a bandeira de vanguarda da modernidade, da "civilização"; ao contrário, por conta de como se conformaram seus interesses de classe, seus compromissos fundamentais seriam construídos com o que lhe fosse vantajoso, independente de estes benefícios serem reflexos de traços "atrasados" ou "modernos" da sociedade brasileira. A Revolução Burguesa brasileira não teria se desenhado através do afã pela modernização contra o "arcaico"; ao contrário, a burguesia como um todo (incluindo aqui a oligarquia) se "ajustara à situação segundo uma linha de múltiplos interesses e de adaptações ambíguas, preferindo a mudança gradual e a composição a uma modernização impetuosa, intransigente e avassaladora." (Fernandes, 2006, p. 241).

Para o autor, ainda, o projeto de desenvolvimento da economia brasileira teria se dado a partir da junção de interesses das burguesias interna e externa; isto porque o modelo de dominação burguesa gerada, nestes marcos, asseguraria estabilidade econômica e política, por um lado, e, por outro, garantiria a reprodução da vida política efetivada pelas elites do país. Em consequência, a dominação burguesa desenvolvida no Brasil teria marcantes características autocráticas, trazidas do passado, e implementadas de diferentes maneiras no presente (Fernandes, 2006).

Dessa forma, na análise do autor, a classe dominante brasileira, por maior que fosse sua diversidade, convergiu em torno de um ponto: sua dominação se dar sob caráter autocrático, mesmo que isto, aparentemente, pudesse ferir os ideais de livre-empresa, ou as bases legais do Estado representativo (Franco, 1997). Portanto, 
foi parte central desta unidade a repressão sobre o proletariado, seu inimigo comum - antes, os seres humanos escravizados; depois, os trabalhadores livres do campo e da cidade.

Assim, a burguesia brasileira sintetizaria o velho e o novo: tanto a antiga aristocracia agrária, que avançava com suas empresas no "mundo dos negócios", quanto os comerciantes da elite dos imigrantes (e seus descendentes), reproduziriam a lógica da dominação burguesa da oligarquia dominante. A oligarquia foi peça-chave na organização do "Brasil moderno", visando a realização de um desenvolvimento capitalista que se desse sob sua hegemonia social, econômica e política. Assim, o desenvolvimento capitalista brasileiro universalizou o controle oligárquico do poder, e os comerciantes, ao se apoiarem nela, encontrariam um ambiente seguro para sua estruturação no mundo capitalista (Fernandes, 2006).

\section{Em sintese}

O debate realizado ao longo deste texto buscou, em primeiro lugar, apresentar algumas características das elaborações de Oliva e de Singer acerca dos conceitos de novo desenvolvimentismo e lulismo, respectivamente. O foco da análise realizada nesta parte foi a caracterização dos autores sobre o grau de autonomia do Estado brasileiro, então dirigido pelos governos PT, para implementar certo projeto político com relativa autonomia.

Após a breve apresentação destas teses, foram trazidos ao debate autores cujas análises permitem a formulação de questionamentos sobre tais leituras. Debatendo com as formulações de Singer, Boito Jr. destaca que a fração de classe diretamente privilegiada nos governos no PT foi a grande burguesia interna, sobrando, aos setores sociais mais pauperizados, algumas concessões, incomparavelmente menores; o subproletariado, assim, não seria uma base social com consistência política, nem programa, para disputar suas demandas no Estado, ou garantir a existência de um governo bonapartista.

Quanto às formulações de Oliva, foram elencadas as contribuições de Bernando Mançano Fernandes, Plínio Arruda Sampaio Jr., além de um apanhado sobre a história social do Brasil a partir de Florestan Fernandes. Neste debate, buscou-se apresentar questões às ideias que defendem a construção de um projeto de interesse nacional único, envolvendo as distintas classes sociais, articuladas a partir de figuras políticas capazes de atenuar suas divergências, deslocando o conflito social (para esquerda $x$ direita, ou ricos $x$ pobres). Dentre os argumentos trazidos, pode-se destacar a manutenção das desigualdades a partir de uma roupagem democrática; a impossibilidade de adoção de políticas econômicas e sociais autônomas, de transformação estrutural e relocalização do país na divisão internacional do trabalho, em uma economia 
periférica; e o perfil histórico de construção da burguesia do país, e sua relação com as classes trabalhadoras.

\section{Conclusões}

O debate em torno do período classificado por Oliva como neodesenvolvimentista, em especial os governos Lula, segue vivo e repleto de polêmicas. Este artigo não tem condições de fazer um amplo apanhado sobre todas elas, mas se propõe a realizar algumas contribuições. Desta longa discussão, alguns pontos devem chamar a atenção para futuras formulações.

Sobre o grau de independência dos governos em questão em relação às classes sociais: este é um ponto de enorme importância nas abordagens apresentadas por Oliva e Singer, e, como visto acima, também passível de discussão. Conforme destacado a partir da bibliografia mobilizada, é difícil medir a profundidade real dessa autonomia através de elementos como a capacidade de lideranças políticas na efetivação da conciliação de interesses de classes sociais antagônicas, de modo que todas passassem a construir um projeto de nação.

Nesse sentido, deve-se considerar também as questões trazidas acerca da relação entre lulismo e bonapartismo, uma vez que, como analisado principalmente por Armando Boito Jr, não se pode afirmar que os governos Lula estavam, politicamente, "acima" das classes sociais, ou mesmo que o subproletariado, uma parcela da população de enorme expressão eleitoral, teria um programa, como classe social, representado pelos governos PT. Retomando a leitura do autor, as políticas "dentro da ordem" implementadas no período não foram consequência das pressões do subproletariado conservador - que, dessa forma, apoiou estes governos, equilibrando a balança da luta de classes; ao contrário, foram resultados do atendimento das exigências da classe verdadeiramente representada pelos governos do período: para o autor, uma fração de classe, a grande burguesia interna. Nesse cenário, o espaço para ações políticas, mesmo que com relativo grau de autonomia, parece ainda menor.

Outro fator essencial à discussão é a desigualdade social. É necessário que as análises considerem este dado com critérios objetivos, destacando, por exemplo, a importância e os efeitos de programas como o Bolsa Família, mas trazendo outras questões estruturais, como elencadas por Bernardo Mançano Fernandes, acerca da concentração de recursos, crédito, e terras no Brasil, mesmo no período chamado neodesenvolvimentista. Dessa forma é possível uma compreensão mais precisa acerca de quais setores foram privilegiados, quais tiveram ganhos reais, e quais foram estes ganhos. 
A história social é também um elemento de importância central. Isto é, partindo das avaliações de Florestan Fernandes, compreendendo a burguesia brasileira como historicamente associada ao capital internacional, sem "aspirações nacionais", diretamente ligada às oligarquias de um país com mais de trezentos anos de escravidão, pode-se questionar a submissão ou aceitação dessa burguesia a um projeto político que implicaria, em tese, ganhos para todas as classes sociais, um projeto comum de sociedade.

Nesse sentido, por fim, é importante destacar o conflito social. As críticas apresentadas pelos autores expressam o tratamento desigual às diferentes classes sociais durante os governos PT. Apontamentos como os de Armando Boito Jr., ao demonstrarem o privilégio de determinados setores da burguesia mostram como, ainda que sob discurso de melhorias para todos, as desigualdades podem ser mantidas - ou, como expresso no caso da questão fundiária, até aprofundadas. A burguesia brasileira, como parte de sua constituição como classe social, tem há séculos lançado mão de soluções violentas contra a classe trabalhadora para a defesa de seus interesses. Não por acaso, os últimos anos demonstram a fragilidade das tentativas de estabelecimento de equilíbrio entre as classes sociais antagônicas no Brasil.

\section{Notas}

Por decisão pessoal, o autor do texto não escreve segundo o novo acordo ortográfico.

1. Doutorando em Sociologia pelo Instituto de Filosofia e Ciências Humanas - Universidade Estadual de Campinas (Unicamp).

2. Cabe destacar que o debate sobre o novo desenvolvimentismo é muito amplo, envolvendo distintas contribuições de diferentes áreas do conhecimento. Por exemplo, para a discussão sobre as origens do neodesenvolvimentismo, ver Bresser-Pereira (2011) e Fonseca (2007); para uma abordagem sobre as relações entre o novo desenvolvimentismo e o contexto de globalização, ver Diniz (2011) e Bresser-Pereira e Gala (2010); para uma discussão acerca do novo desenvolvimentismo e a relação entre Estado e setor privado, ver Bresser-Pereira e Diniz (2009); para o debate entre neodesenvolvimentismo e as funç̃es do Estado, ver Diniz (2011) e Cepêda (2012); para uma análise econômica do novo desenvolvimentismo, ver Oreiro (2012) e Beluzzo (2013); para uma análise crítica sobre o emprego no neodesenvolvimentismo, ver Pochmann (2012); para uma comparação entre o período chamado neodesenvolvimentista e os governos da década de 1990, ver Sader (2013) e Gonçalves (2012), etc.

3. Neste ponto, é importante destacar que, para Oliva, a agricultura corresponde ao conjunto dos agentes e classes sociais envolvidos na produção agrícola; ou seja, ao destacar a agricultura, o autor faz referência ao agronegócio, às pequenas unidades de produção familiar, aos trabalhadores assalariados rurais, etc. 
4. A "crise do mensalão" foi uma crise política que explode a partir da denúncia de compra de votos de parlamentares por parte do governo. Para mais informações, ver Singer (2012).

5. Isto significa que, para Boito Jr., "a grande burguesia interna, nas suas disputas com a fração burguesa perfeitamente integrada ao grande capital financeiro internacional, converteu-se em força dirigente de uma ampla e heterogênea frente política que poderíamos denominar neodesenvolvimentista" (Boito Jr., 2013, p. 178).

\section{Referências}

Beluzzo, L. G. (2013). Os anos do povo. Em E. Sader (Org.), 10 anos de governos pós-neoliberais no Brasil: Lula e Dilma (pp. 103-110). São Paulo: Boitempo.

Bresser-Pereira, L. C. (2011). O Brasil e o novo desenvolvimentismo. Interesse Nacional, (13), 76-85.

Bresser-Pereira, L. C., e Diniz, E. (2009). Empresariado industrial, democracia e poder político. Novos Estudos, (84), 83-99.

Bresser-Pereira, L. C., e Gala, P. (2010). Macroeconomia estruturalista do desenvolvimento. Revista de Economia Política, 30(4), 663-686.

Boito Jr., A. (2013). O lulismo é um tipo de bonapartismo? Uma crítica às teses de André Singer. Crítica Marxista, 37, 171-206.

Boito Jr., A., e Galvão, A. (Orgs.) (2012). Política e classes sociais no Brasil nos anos 2000. São Paulo: Ed. Alameda.

Cepêda, V. (2012). Inclusão, democracia e novo desenvolvimentismo. Estudos Avançados, 26(75), 77-90.

Diniz, E. (2011). O contexto internacional e a retomada do debate sobre desenvolvimento no Brasil contemporâneo (2000/2010). DADOS - Revista de Ciências Sociais, 54(4), 493-532.

Farah, T. (2015, 09 de janeiro). Concentração de terra cresce e latifúndios equivalem a quase três estados de Sergipe. O Globo. Disponível em https:/ /oglobo.globo.com/brasil/concentracao-de-terra-cresce-latifundios-equival em-quase-tresestados-de-sergipe-15004053.

Fernandes, B. M. (2013). A reforma agrária que o governo Lula fez e a que pode ser feita. Em E. Sader (Org.), 10 anos de governos pós-neoliberais no Brasil: Lula e Dilma (pp. 191-206). Rio de Janeiro: Flacso.

Fernandes, F. (2006). A revolução burguesa no Brasil. São Paulo: Globo.

Fonseca, P. C. D. (2007). O ecletismo inovador: Bresser-Pereira e o desenvolvimento brasileiro. Economia e Sociedade, 16(1), 1-43.

Franco, M. S. C. (1997). Homens livres na ordem escravocrata. São Paulo: Editora da Unesp.

Furtado, C. (1968). Subdesenvolvimento e estagnação na América Latina. Rio de Janeiro: Civilização Brasileira.

Gonçalves, R. (2012). Novo desenvolvimentismo e liberalismo enraizado. Serv. Soc. Soc., (112), 637-671. 
Moimaz, R. S. (2015). Breve contribuição ao debate sobre o novo desenvolvimentismo no Brasil (Dissertação de mestrado). Instituto de Filosofia e Ciências Humanas/Unicamp, Campinas, Brasil.

Oliva, A. M. (2010). As bases do novo desenvolvimentismo: Análise do governo Lula (Tese de doutoramento). Instituto de Economia/Unicamp, Campinas, Brasil.

Oreiro, J. L. C. (2012). Novo-desenvolvimentismo, crescimento econômico e regimes de política macroeconômica. Estudos avançados, 26(75), 29-40.

Pochmann, M. (2012). Nova classe média?. São Paulo: Boitempo.

Prado Jr., C. P. (1987). A questão agrária no Brasil. São Paulo: Brasiliense.

Sader, E. (Org.) (2013). A construção da hegemonia pós-neoliberal. Em 10 anos de governos pós-neoliberais no Brasil: Lula e Dilma (pp. 135-144). Rio de Janeiro: FLACSO.

Sampaio Jr., P. A. (2012). Desenvolvimentismo e neodesenvolvimentismo: Tragédia e farsa. Serviç̧o Social \& Sociedade, (112), 672-688.

Singer, A. (2009). Raízes sociais e ideológicas do lulismo. Novos estudos, (85), 83-102.

Singer, A. (2012). Os sentidos do lulismo: Reforma gradual e pacto conservador. São Paulo: Companhia das Letras.

Vargas, T. P. (2009). Particularidades da formação do capitalismo dependente brasileiro - O debate entre Cardoso e Marini (Monografia em Ciências Sociais). Instituto de Filosofia e Ciências Humanas/Unicamp, Campinas, Brasil.

Data de submissão: 01/05/2019 | Data de aceitação: 23/12/2019 